\title{
ChemComm
}

\section{Rapid and efficient synthesis of $\left[{ }^{11} \mathrm{C}\right]$ ureas via the incorporation of $\left[{ }^{11} \mathrm{C}\right] \mathrm{CO}_{2}$ into aliphatic and aromatic amines $\dagger$}

Cite this: Chem. Commun., 2013, 49, 8193

Received 29th May 2013, Accepted 29th July 2013

DOI: $10.1039 / c 3 c c 44046 j$

www.rsc.org/chemcomm

\author{
Abdul Karim Haji Dheere, Nadiya Yusuf and Antony Gee*
}

A rapid urea radiolabelling methodology has been developed. $\left[{ }^{11} \mathrm{C}\right] \mathrm{CO}_{2}$ was activated by 1,8-diazabicycloundec-7-ene (DBU) in the presence of aliphatic and aromatic amines and reacted with Mitsunobu reagents to produce asymmetric ${ }^{11} \mathrm{C}$ radiolabelled ureas in high radiochemical yields.

Positron emission tomography (PET) is a non-invasive molecular imaging technique that is used for medical diagnosis, drug development, and the understanding of normo- and pathophysiology. ${ }^{1}$ Carbon-11 $\left(t_{1 / 2}=20.4 \mathrm{~min}\right)$ is a commonly used radio-isotope for PET imaging, the ubiquity of carbon in all naturally occurring organic compounds making it an attractive radio-isotope for molecular imaging. Substituting carbon-12 $\left({ }^{12} \mathrm{C}\right)$ in biologically active molecules with radioactive ${ }^{11} \mathrm{C}$ has no effect on the chemistry or the biological activity of the molecule. ${ }^{2}$ Cyclotron-produced ${ }^{11} \mathrm{C}$ is commonly prepared in the form of $\left[{ }^{11} \mathrm{C}\right]$ carbon dioxide $\left(\left[{ }^{11} \mathrm{C}\right] \mathrm{CO}_{2}\right)$ by the ${ }^{14} \mathrm{~N}(\mathrm{p}, \alpha){ }^{11} \mathrm{C}$ nuclear reaction. Due to its poor reactivity, $\left[{ }^{11} \mathrm{C}\right] \mathrm{CO}_{2}$ is typically converted into more reactive synthons such as $\left[{ }^{11} \mathrm{C}\right]$ methyl iodide or triflate and subsequently used to radiolabel molecules of biological interest. ${ }^{3}$ Although these labelling synthons are useful, not all target molecules are accessible by these synthons and their preparation takes several minutes with a concomitant decrease in ${ }^{11} \mathrm{C}$ radioactivity due to decay. The development of methods to efficiently label compounds directly with $\left[{ }^{11} \mathrm{C}\right] \mathrm{CO}_{2}$ is therefore of significant interest.

To overcome the low reactivity of $\mathrm{CO}_{2}$, bases such as 1,8-diazabicycloundec-7-ene (DBU) or 2-tert-butylimino-2-diethylamino-1,3-dimethylperhydro-1,3,2-diazaphosphorine (BEMP) have recently been utilised as $\mathrm{CO}_{2}$ activating agents in the synthesis of ${ }^{11}$ C-labelled organic molecules. ${ }^{4,5}$ These methods, however, produce very poor yields for unreactive aromatic amines, or the reactions are limited to a specific product. $^{6}$

Division of Imaging Sciences and Biomedical Engineering, King's College London, UK SE1 7EH. E-mail: antony.gee@kcl.ac.uk; Fax: +44 (0)20 718 85442; Tel: +44 (0)20 71888366

† Electronic supplementary information (ESI) available. See DOI: 10.1039/ c3cc44046j

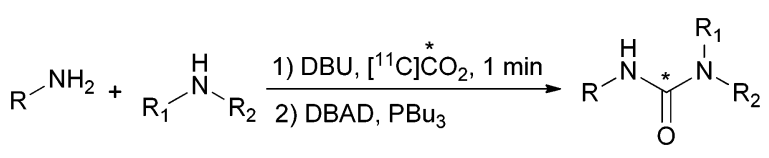

Scheme 1 Synthesis of $\left[{ }^{11} \mathrm{C}\right]$ urea with $\left[{ }^{11} \mathrm{C}\right] \mathrm{CO}_{2}$.

We report herein a rapid $\left[{ }^{11} \mathrm{C}\right] \mathrm{CO}_{2}$ radiolabelling methodology which overcomes these limitations. DBU was used to trap the cyclotron-produced $\left[{ }^{11} \mathrm{C}\right] \mathrm{CO}_{2}$ which was subsequently reacted with aliphatic, benzylic and aromatic amines (Scheme 1) to synthesise $\left[{ }^{11} \mathrm{C}\right]$ ureas in a highly efficient manner.

Ureas are found in a plethora of biologically active molecules as has been extensively reported in the literature. ${ }^{7}$ The method reported herein provides a methodology to label this class of compounds with carbon-11.

Model reactions were initially conducted using nonradioactive $\mathrm{CO}_{2} \cdot{ }^{8}$ Compound 3 was subsequently chosen as the initial model reaction for optimisation with $\left[{ }^{11} \mathrm{C}\right] \mathrm{CO}_{2}$.

$\left[{ }^{11} \mathrm{C}\right] \mathrm{CO}_{2}$ from the cyclotron target was bubbled in a stream of helium gas at a flow rate of $1.4 \mathrm{ml} \mathrm{min}^{-1}$ post target depressurisation directly into a solution containing a primary amine, a secondary amine and DBU in acetonitrile for one minute. The solution was stirred for one minute prior to the addition of Mitsunobu reagents di-tert-butyl azodicarboxylate (DBAD) and tributylphosphine $\left(\mathrm{PBu}_{3}\right)$.

Initially, experiments were performed in a number of different solvents at $40{ }^{\circ} \mathrm{C}$ (Table 1, entries 1-3) with the aim of identifying the best solvent for the reaction. Acetonitrile trapped cyclotronproduced $\left[{ }^{11} \mathrm{C}\right] \mathrm{CO}_{2}$ very efficiently when bubbled directly into the reaction mixture (>95\%), while DMSO and DMF were slightly less efficient (80-90\%).

Moderate radiochemical yields (46\%) of the desired $\left[{ }^{11} \mathrm{C}\right]$ ureas were observed using acetonitrile as a solvent while DMF and DMSO gave yields of $13 \%$ and $18 \%$ respectively, despite good $\left[{ }^{11} \mathrm{C}\right] \mathrm{CO}_{2}$ trapping (Table 1). Acetonitrile was therefore selected as the solvent of choice for subsequent reactions.

RCY was determined by radio-HPLC and defined as the amount of labelled $\left[{ }^{11} \mathrm{C}\right]$ urea as a percentage of the cyclotron-produced 
Table 1 Reaction optimisation

\begin{tabular}{|c|c|c|c|c|}
\hline & $\mathrm{NH}_{2}$ & $\begin{array}{l}\stackrel{*}{\mathrm{C}} \mathrm{O}_{2} \\
\mathrm{PBu}_{3}\end{array}$ & $\|_{*}^{0}$ & \\
\hline Entry $^{a}$ & Solvent & $T\left({ }^{\circ} \mathrm{C}\right)$ & Time (min) & $\mathrm{RCY}^{b}(\%)$ \\
\hline 1 & MeCN & 40 & 5 & $46 \pm 7$ \\
\hline 2 & DMF & 40 & 5 & $13 \pm 3$ \\
\hline 3 & DMSO & 40 & 5 & $18 \pm 6$ \\
\hline $4^{c}$ & MeCN & 25 & 5 & 0 \\
\hline 5 & MeCN & 25 & 5 & $8 \pm 1$ \\
\hline 6 & MeCN & 60 & 5 & $26 \pm 12$ \\
\hline 7 & $\mathrm{MeCN}$ & 50 & 5 & $95 \pm 3$ \\
\hline 8 & MeCN & 50 & 1 & $96 \pm 2$ \\
\hline $\begin{array}{l}{ }^{a} \text { React } \\
(27.5 \quad \\
400 \mu \mathrm{n} \\
\text { concen }\end{array}$ & $\begin{array}{l}\text { nditions } \\
\text { DBU }(0 \\
\text { tonitrile } \\
9\end{array}$ & $\begin{array}{l}\text { lary am } \\
\text { ol), } \mathrm{Mi} \\
\text { 3. }{ }^{b} \text { Det }\end{array}$ & $\begin{array}{l}8.3 \mu \mathrm{mol}) \text {, se } \\
\text { bu reagents } \\
\text { ed by radio-H }\end{array}$ & $\begin{array}{l}\text { ry amine } \\
\mu \text { mol) in } \\
\text { Reduced }\end{array}$ \\
\hline
\end{tabular}

$\left[{ }^{11} \mathrm{C}\right] \mathrm{CO}_{2}$ trapped in solution obtained directly from the cyclotron and corrected for radioactive decay.

When the reactions were carried out at lower reagent concentrations (Table 1 , entry 4 ), no $\left[{ }^{11} \mathrm{C}\right]$ radiolabelled product was observed despite efficient $\left[{ }^{11} \mathrm{C}\right] \mathrm{CO}_{2}$ trapping. ${ }^{9}$

The temperature dependency of the reaction was subsequently examined. Loss of $\left[{ }^{11} \mathrm{C}\right] \mathrm{CO}_{2}$ from the reaction vial was observed when the reactions were performed at $60{ }^{\circ} \mathrm{C}$. Reactions at $50{ }^{\circ} \mathrm{C}$ avoided these losses and resulted in over $95 \%$ incorporation of the $\left[{ }^{11} \mathrm{C}\right] \mathrm{CO}_{2}$ into the target radiolabelled

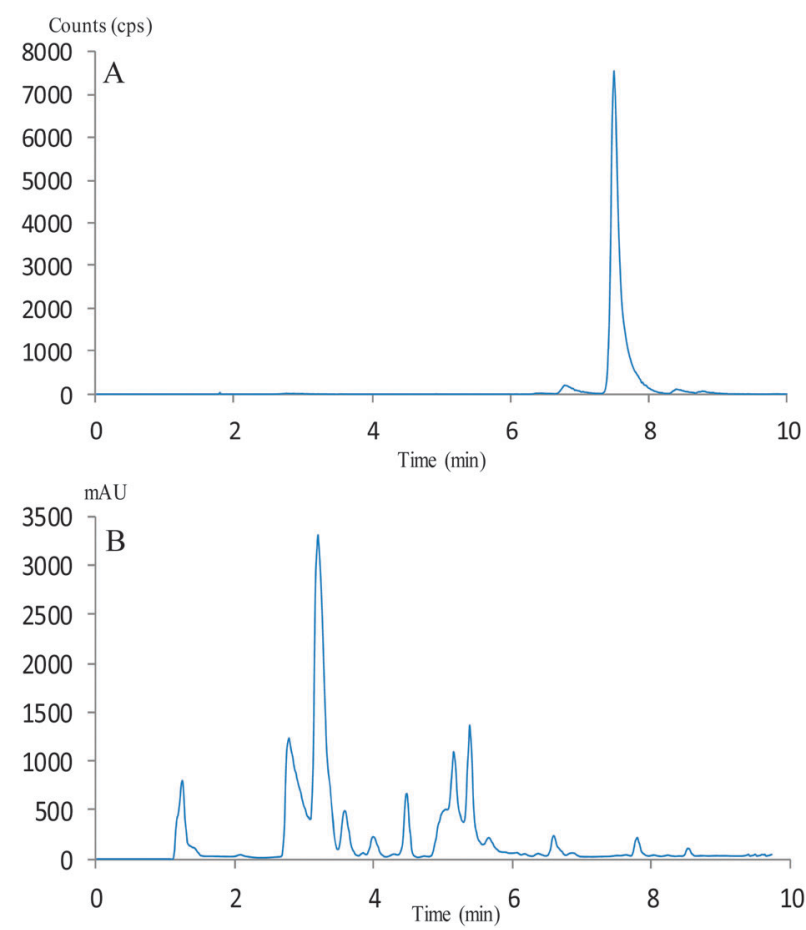

Fig. 1 HPLC chromotogram of the crude radiolabelled product (Table 1, entry 8). (A) Radioactivity (counts per second) target compound 3 at $R_{\mathrm{t}} 7.30 \mathrm{~min}$. (B) UV absorption ( $254 \mathrm{~nm}$ ) of compound 1 at $R_{\mathrm{t}} 3.25 \mathrm{~min}$, compound $2 R_{\mathrm{t}} 3.45 \mathrm{~min}$ and by-products at $5.00 \mathrm{~min}, 5.30 \mathrm{~min}$ and $5.50 \mathrm{~min}$.
Table 2 Radiolabelling various aliphatic, benzylic and aromatic amines with $\left[{ }^{11} \mathrm{C}\right] \mathrm{CO}_{2}$

Entry ${ }^{a}$

molecules (Table 1, entry 7). Reducing the reaction time from 5 to 1 minute still resulted in a RCY of 96\% (Table 1, entry 8 and Fig. 1).

The conditions for the model reaction were subsequently applied to the radiosynthesis of various asymmetric ureas using a range of aliphatic, benzylic and aromatic amines (Table 2).

The reactions between benzylic primary amines and the secondary amine, tetrahydroisoquinoline (Table 1 , entry 8 ) resulted in high RCY while the reaction with $N$-methylbenzylamine produced slightly lower yields of the $\left[{ }^{11} \mathrm{C}\right]$ urea (Table 2 , entry 1). The high yields for tetrahydroisoquinoline can be explained by the rigidity of the molecule, having a locked planer confirmation and less steric hindrance.

Interestingly, RCYs of similar magnitudes were observed when a less reactive aromatic primary amine was used in place of a benzylic amine to form the target radiolabelled molecules (Table 2, entries 2 and 3).

The effect of functional groups on aromatic amines was also studied. Reactions with the electron rich aromatic amines $m$-toluidine, and $p$-anisidine resulted in over $80 \%$ RCY (Table 2, entries 5 and 6) and even poor nucleophiles such as 
4-nitroaniline reacted efficiently, producing high RCY of $85 \%$ (Table 2, entry 4). The reaction favours the formation of asymmetric $\left[{ }^{11} \mathrm{C}\right]$ ureas despite primary amines being present in excess of $\left[{ }^{11} \mathrm{C}\right] \mathrm{CO}_{2}$. In the absence of secondary amines, various by-products are observed resulting in reduced RCY (Table 2, entry 7).

In conclusion, a rapid and robust methodology for the radiosynthesis of ureas has been developed. The method incorporates $\left[{ }^{11} \mathrm{C}\right] \mathrm{CO}_{2}$ directly into aliphatic, benzylic and aromatic amines producing the target radiolabelled ureas in high RCY. Overcoming limitations of previous methods, even poorly reactive aromatic amines gave excellent RCY's of asymmetric $\left[{ }^{11} \mathrm{C}\right]$ ureas within one minute after the addition of Mitsunobu reagents.

This novel radiolabelling methodology opens up new possibilities for ${ }^{11} \mathrm{C}$ radiolabelling molecules for in vivo molecular imaging applications.

\section{Notes and references}

1 (a) C. R. Child, S. Kealey, H. Jones, P. W. Miller, A. J. P. White, A. D. Gee and N. J. Long, Dalton Trans., 2011, 40, 6210-6215; (b) V. J. Cunningham, C. A. Parker, E. A. Rabiner, A. D. Gee and R. N. Gunn, Drug Discovery Today, 2005, 2, 311-315; (c) J. Wang and L. Maurer, Curr. Top. Med. Chem., 2005, 5, 1053-1075; (d) N. Oriuchi, T. Higuchi, T. Ishikita, M. Miyakubo, H. Hanaoka, Y. Iida and K. Endo, Cancer Sci., 2006, 97, 1291-1297.

2 (a) P. W. Miller, N. J. Long, R. Vilar and A. D. Gee, Angew. Chem., Int. Ed., 2008, 47, 8998-9033; (b) F. Lodi, C. Malizia, P. Castellucci, G. Cicoria, S. Fanti and S. Boschi, Nucl. Med. Biol., 2012, 39, 447-460.

3 (a) A. A. Wilson, A. Garcia, L. Jin and S. Houle, Nucl. Med. Biol., 2000, 27, 529-532; (b) J. R. Atack, P. Scott-Stevens, J. S. Beech, T. D. Fryer, J. L. Hughes, M. C. Cleij, J.-C. Baron, J. C. Clark, R. J. Hargreaves and
F. I. Aigbirhio, J. Pharmacol. Exp. Ther., 2007, 320, 1030-1037; (c) J.-K. Chung, Y. Kim, S.-k. Kim, Y. Lee, S. Paek, J. Yeo, J. Jeong, D. Lee, H. Jung and M. Lee, Eur. J. Nucl. Med., 2002, 29, 176-182; (d) R. Bolton, J. Labelled Compd. Radiopharm., 2001, 44, 701-736.

4 (a) J. M. Hooker, A. T. Reibel, S. M. Hill, M. J. Schueller and J. S. Fowler, Angew. Chem., Int. Ed., 2009, 48, 3482-3485; (b) A. A. Wilson, A. Garcia, S. Houle and N. Vasdev, Org. Biomol. Chem., 2010, 8, 428-432; (c) P. J. Riss, S. Lu, S. Telu, F. I. Aigbirhio and V. W. Pike, Angew. Chem., Int. Ed., 2012, 51, 2698-2702; (d) D. J. Heldebrant, P. G. Jessop, C. A. Thomas, C. A. Eckert and C. L. Liotta, J. Org. Chem., 2005, 70, 5335-5338; (e) M. L. Gray, K. J. Champagne, D. Fauth, J. P. Baltrus and H. Pennline, Int. J. Greenhouse Gas Control, 2008, 2, 3-8.

5 (a) L. D. Field, E. T. Lawrenz, W. J. Shaw and P. Turner, Inorg. Chem., 2000, 39, 5632-5638; (b) M. R. Sievers and P. B. Armentrout, Inorg. Chem., 1999, 38, 397-402; (c) Y. Hori, H. Wakebe, T. Tsukamoto and O. Koga, Surf. Sci., 1995, 335, 258-263; (d) Y. Gu, F. Shi and Y. Deng, J. Org. Chem., 2003, 69, 391-394; (e) W. McGhee and D. Riley, J. Org. Chem., 1995, 60, 6205-6207.

6 (a) E. W. van Tilburg, A. D. Windhorst, M. van der Mey and J. D. M. Herscheid, J. Labelled Compd. Radiopharm., 2006, 49, 321-330; (b) A. A. Wilson, A. Garcia, S. Houle, O. Sadovski and N. Vasdev, Chem.-Eur. J., 2011, 17, 259-264.

7 (a) C. P. Decicco, J. L. Seng, K. E. Kennedy, M. B. Covington, P. K. Welch, E. C. Arner, R. L. Magolda and D. J. Nelson, Bioorg. Med. Chem. Lett., 1997, 7, 2331-2336; (b) Q.-Z. Zheng, K. Cheng, X.-M. Zhang, K. Liu, Q.-C. Jiao and H.-L. Zhu, Eur. J. Med. Chem., 2010, 45, 3207-3212; (c) K. Sanphanyaa, S. Wattanapitayakul, O. Prangsaengtongc, M. Joc, K. Koizumi, N. Shibaharac, A. Pripremd, V. Fokine and O. Vajragupta, Bioorg. Med. Chem. Lett., 2012, 22, 3001-3005.

8 (a) S. L. Peterson, S. M. Stucka and C. J. Dinsmore, Org. Lett., 2010, 12, 1340-1343; (b) C. J. Dinsmore and S. P. Mercer, Org. Lett., 2004, 6, 2885-2888; (c) K. C. K. Swamy, N. N. B. Kumar, E. Balaraman and K. V. P. P. Kumar, Chem. Rev., 2009, 109, 2551-2651.

9 Reduced concentration conditions: primary amine $(6.1 \mu \mathrm{mol})$, secondary amine $(9.1 \mu \mathrm{mol})$, DBU $(0.3 \mu \mathrm{mol})$, Mitsunobu reagents $(12.2 \mu \mathrm{mol})$ and $400 \mu \mathrm{mol}$ acetonitrile. 